\title{
RESEARCH OF CHANGE IN FRACTION COMPOSITION OF VEHICLE GASOLINE IN THE MODIFICATION OF ITS BIODETHANOL IN THE CAVITATION FIELD
}

\author{
Aleksey Tselishchev \\ Department of Chemical Engineering and Ecology ${ }^{1}$ \\ atp00@ukr.net \\ Marina Loriya \\ Department of Electronic Apparations ${ }^{1}$ \\ atp01@ukr.net \\ Sergey Boychenko \\ Department of Ecology ${ }^{2}$ \\ boichenko@ukr.net \\ Sergey Kudryavtsev \\ Department of Chemical Engineering and Ecology \\ sergeykudryavtsevsnu@gmail.com \\ Vasil Laneckij \\ Department of Gas and Gas Systems ${ }^{2}$ \\ laneckijvasil@gmail.com \\ ${ }^{1}$ Volodymyr Dahl East Ukrainian National University \\ 59-a Tsentralnyi ave., Severodonetsk, Ukraine, 93400 \\ ${ }^{2}$ National Aviation University \\ 1 Komarova ave., Kyiv, Ukraine, 03065
}

\begin{abstract}
The influence of bioethanol content and parameters of the cavitation field on the quality indicators of motor gasolines: volatility and octane number is studied. Studying the effect of bioethanol and cavitation treatment of bioethanol-gasoline mixture will make it possible to produce automotive fuels for different climatic zones, or winter (summer) versions of gasolines. The use of bioethanol and cavitation treatment of a bioethanol-gasoline mixture affect the fractional composition of motor gasoline and its volatility. The optimal content of the biocomponent, at which there is an increase in the volatility of gasoline, is established Also the results of the octane number change are presented depending on the intensity of cavitation treatment for gas condensate with the addition of bioethanol. The influence of bioethanol content on the increase in octane number during cavitation treatment is determined.

It is found that the introduction of bioethanol into the composition of gasoline leads to an improvement in its volatility. In this case, cavitation treatment makes it possible to obtain a mixture resistant to delamination.

The addition of bioethanol leads to an adequate increase in light fractions during mechanical mixing and to a change in the fractional composition of the bioethanol-gasoline mixture during cavitation treatment.

The addition of bioethanol in amounts up to $10 \%$ leads to a decrease in the saturated vapor pressure during cavitation treatment of bioethanol-gasoline mixtures, and an increase in the bioethanol content up to $20 \%$ leads to an increase in the saturated vapor pressure, which is explained by a change in the chemical composition of fuel components in comparison with the mechanical method of preparing mixtures.

By cavitation treatment it is possible to change the fractional composition, the pressure of saturated vapors and the volatility of bioethanol-gasoline mixtures, making cavitation a promising energy-saving process for the production of gasoline for various climatic conditions.
\end{abstract}

Keywords: bioethanol, cavitation field, gasoline volatility, fractional composition, octane number. 


\section{Introduction}

The composition of motor gasolines and their compliance with the EURO-3 (4.5) standards is established by DSTU 7687:2015. According to this standard, gasolines may contain up to $3 \%$ methanol, or up to $10 \%$ bioethanol, up to $12 \%$ isopropanol, up to $15 \%$ isobutanol, other alcohols and ethers. It is allowed to use other oxygen-containing compounds with a boiling point of no more than $483 \mathrm{~K}$.

Bioethanol is a promising feedstock to be added to motor gasolines. Compared to other oxygen-containing compounds, it is less toxic, more readily available on the market, and has good environmental characteristics. The use of bioethanol for the modification of motor gasolines is becoming more and more popular. In the new DSTU 7687:2015, classes of motor gasolines are distinguished depending on the amount of bioethanol used for their modification: E5 (up to $5 \%$ by volume of bioethanol) E7 (5-7\% by volume); E10 (up to $10 \%$ by volume bioethanol). In some countries (USA, Brazil, China) bioethanol-hydrocarbon mixtures E85, E95 and even E100 are used. The consumption of such fuel is constantly growing. Accordingly, the consumption of bioethanol is constantly growing. So in 2005, the global consumption of bioethanol amounted to 36 million tons, and in 2019 it has already exceeded 60 million tons. According to experts, in 2020, about $15 \%$ of the world's automotive fuel will be obtained from bio-raw materials. So bioethanol is a very promising raw material for the production of gasoline. However, the use of bioethanol as an additive to motor gasoline has several significant problems. The most important problem is the physical instability of the alcohol-gasoline mixture, namely its stratification.

From the above, it is possible to conclude that the study of the processes of modification of gasolines with bioethanol is an urgent scientific and practical task [1].

The application of the technology of cavitation treatment of bioethanol-gasoline mixtures for the creation of high-octane gasolines is promising [2]. As it is known, cavitation is a phenomenon of the appearance of bubbles (cavities) in a dropping liquid. If the pressure is reduced due to the appearance of large local velocities in the flow of a moving droplet liquid, then cavitation is called dynamic. And if, due to the passage of acoustic waves into the liquid - acoustic. The energy of the collapse of the bubbles leads, in particular, to the homogenization of the product being processed. This is an important factor, given the high tendency of bioethanol-gasoline mixtures to stratification [3, 4].

Today, cavitation treatment is used quite successfully to solve the problem of improving certain properties of both fuel oil fractions and commercial oil products.

The use of bioethanol and cavitation treatment of a bioethanol-gasoline mixture affects the fractional composition of motor gasoline and its volatility. In the future, the study of these patterns will make it possible to produce automobile fuels for different climatic zones, or winter (summer) versions of gasoline.

\section{Literature review and problem statement}

Previous studies [5-7] have shown that the introduction of bioethanol into the gas condensate and the cavitation treatment of the mixture can significantly increase the detonation resistance of gasolines. The efforts of researchers are aimed at finding the optimal parameters of the cavitation field, which will make it possible to achieve the octane number $(\mathrm{ON})$ indicators, sufficient for the production of gasoline A-92, A-95 and higher, with minimal energy consumption.

The mere introduction of bioethenol by mechanical mixing with gasoline does not allow successfully solving the problems of stratification of bioethane-gasoline mixtures, therefore, the use of cavitation in this case is advisable, since it improves the homogenization of the mixture. The work [8] shows the design of a cavitation reactor for processing hydrocarbon raw materials. A feature of this reactor is that its design allows one to obtain three zones of dynamic cavitation. It is shown that in a cavitation field, hydrogen peroxide decomposes into hydroxyl radicals, which subsequently take part in the synthesis of methanol. So in such a reactor it is possible not only to obtain a homogeneous liquid from gasoline and bioethanol, but also to carry out chemical transformations of gasoline [9].

In [10], a cavitation unit for processing hydrocarbon raw materials is presented. The installation allows to carry out the processing process with a pressure of up to $30 \mathrm{MPa}$. It was found that 
the transformation of $n$-alkanes in the presence of hydrogen peroxide into alcohols, namely methanol, occurs at a pressure of 9-21 MPa. Moreover, the maximum conversion of n-alkanes occurs at a pressure of $19 \mathrm{MPa}$. In work [5], the influence of cavitation treatment of gasoline on the change in its $\mathrm{ON}$ is also investigated. It is shown that during cavitation treatment of gasoline at a pressure of about $20 \mathrm{MPa}$, its ON increases by $\sim 4$ units. This is due to the conversion of linear alkanes with low $\mathrm{ON}$ to isoalkanes and unsaturated hydrocarbons, which have a high ON.

In [11], the effect of hydrogen peroxide in a cavitation field on the process of converting linear alkanes into high-octane components of motor fuels, including methanol, was studied. It is found that without hydrogen peroxide, the process proceeds mainly in the direction of toluene synthesis. Its concentration in processed products increases to $5 \%$. When an aqueous solution of hydrogen peroxide is introduced into the system, methanol appears along with toluene. The methanol concentration under the experimental conditions reaches $3 \%$. The mass composition of gasoline before and after cavitation treatment is determined. Changes in the groups of hydrocarbons from the composition of gasoline, depending on the pressure, occurring during processing with and without hydrogen peroxide are investigated. The introduction of hydrogen peroxide into gasoline supplied for cavitation processing makes it possible to increase the ON of gasoline to 14 units.

Research into the influence of cavitation on the quality of gasoline is very relevant. There are publications, for example [12], which disclose various aspects of the influence of cavitation on various characteristics of motor gasoline fuel.

The study of the influence of the cavitation process on such important characteristics of a bioethanol-gasoline mixture as fractional composition and volatility will make it possible in the future to develop the foundations of the technology for the production of motor gasolines with different volatility indicators for different climatic conditions.

The aim of research is to determine the effect of bioethanol content and parameters of the cavitation field on the volatility and fractional composition of the bioethanol-gasoline mixture when modified in a cavitation field.

To achieve this aim, the following objectives are set:

- to modernize the laboratory installation for cavitation treatment of bioethanol-gasoline mixtures of mixtures to study the effect of cavitation parameters on the fractional composition and volatility;

- to investigate the effect of bioethanol content and the effect of cavitation on the volatility of bioethanol-gasoline mixtures;

- to study the effect of bioethanol content and the effect of cavitation on the fractional composition of bioethanol-gasoline mixtures.

\section{Description of the laboratory setup, methodology of the experiment and analysis of exper- imental data}

3. 1. Materials and methods for studying the effect of cavitation on the fractional composition of bioethanol-gasoline mixtures

Experimental studies were carried out on an original laboratory unit, schematically shown in Fig. 1.

The experiments were carried out in this way. Gasoline is mixed with alcohol in the required proportion and enters container $\mathrm{C}$, from where the raw material is dosed by the regulator $\mathrm{R}$ using the high-pressure pump HPP to the nozzle-reactor N. The nozzle-reactor allows creating a pressure at the outlet of the nozzle at the level of $9.0 \mathrm{MPa}$. The pressure is measured by the PI manometer, and the pressure change is possible by replacing the nozzle. At the outlet of the nozzle, cavitation cavities are formed, which are mini-reactors in which chemical transformations take place. Cavitation cavities are also formed when droplets of raw material, escaping from the nozzle of the nozzle at a speed of more than $140 \mathrm{~m} / \mathrm{s}$, collide with the walls of the reactor and with a cone-shaped baffle located in the separator $\mathrm{S}$ right in front of the nozzle.

Separator S collects raw materials and degassing them from air and possible gaseous products. The gas phase at the top of the separator is analyzed chromatographically for hydrocarbon content. The liquid phase, which is the target product, is sent for analysis of octane number and 
chemical composition. The intensity of cavitation treatment is regulated both by replacing the nozzle (changing the pressure) and by varying the number of cavitation treatment cycles. For this, the possibility of recycling raw materials through a laboratory installation is provided.

Fig. 2 shows a general view of the laboratory unit (Fig. 2, a), which was developed by the authors, and the external view of the cavitation reactor (Fig. 2, b).

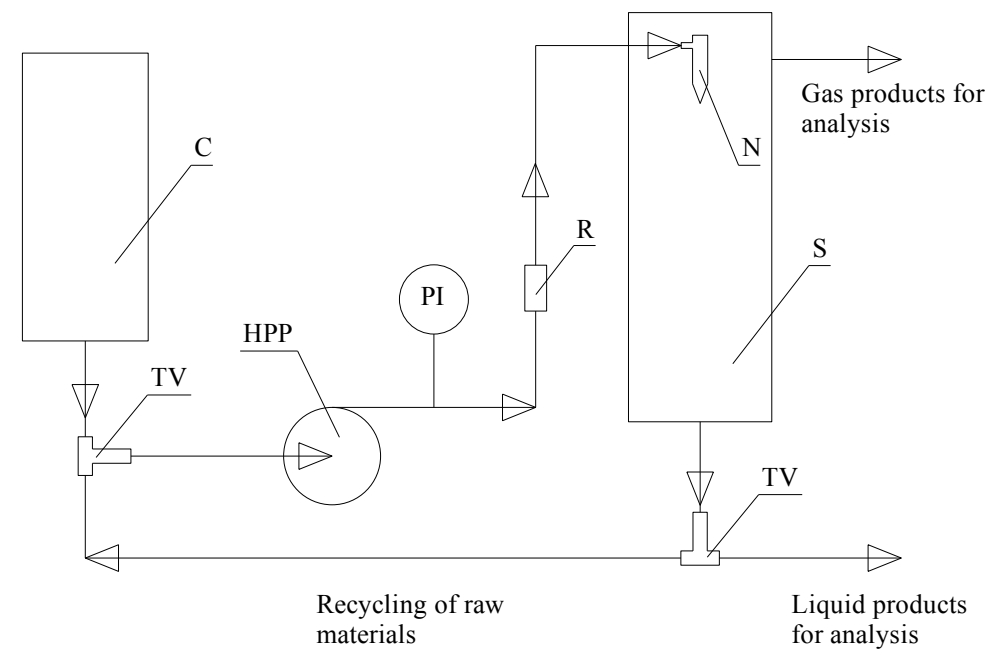

Fig. 1. Laboratory unit for studying the effect of cavitation treatment on the octane number and composition of gasolines modified with alcohols: $\mathrm{C}$ - a container with raw materials (a mixture of gasoline and alcohol), $\mathrm{S}$ - a separator tank for products, $\mathrm{N}$ - a nozzle-reactor, which performs cavitation processing of raw materials, HPP - high pressure pump, TVA - three-way valve with adjustment function, TV - three-way valve, PI - manometer, $\mathrm{R}$ - flow regulator

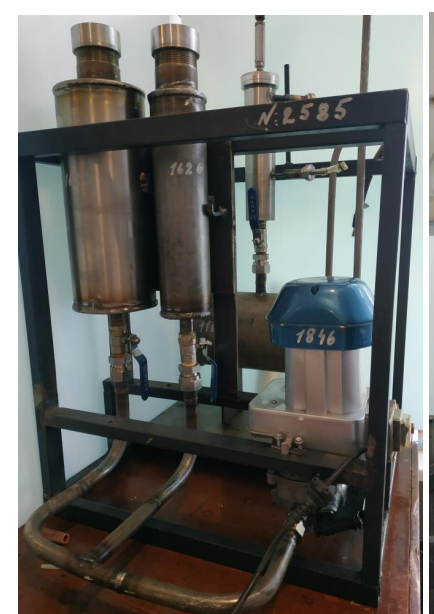

$a$

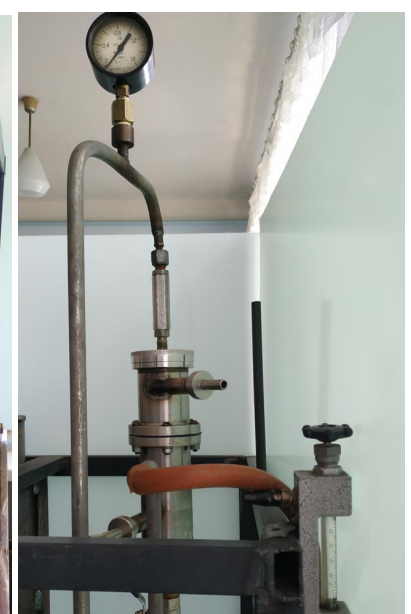

$b$

Fig. 2. Photo of the laboratory author's unit for studying the effect of cavitation on the volatility and fractional composition of bioethanol-gasoline mixtures: $a$ - general view; $b$ - cavitation reactor

Analysis of the process of modification of motor gasolines in a cavitation field made it possible to conclude that the output parameters of the process (fractional composition and volatility) are regulated by changing the mixture flow rate, bioethanol content and pressure at the inlet of the nozzle.

Fractional composition of raw materials and products was determined according to GOST 2177-99 (ISO 3405-88) Petroleum products. Methods for determining fractional composition (Petroleum products. Methods for determining fractional composition). The octane number 
according to the research method was determined using a portable SHATOX SX-150 octane meter with a measurement error of no more than 0.2 points. The stability of raw materials and products was determined according to DSTU 7685:2015 Gasoline. Method for determination of oxidation stability (induction period method). The saturated vapor pressure was determined according to 6 ASTM D323-08 Standard test method for vapor pressure of petroleum products (Reid method) (Standard test method for the vapor pressure of petroleum products (Reid method)). The content of individual hydrocarbons, alcohols, ethers in the samples was determined chromatographically on a Kristall-2000 chromatograph.

\section{Results of experimental studies of the influence of the parameters of the cavitation field on the physical stability of gasoline}

To establish the influence of the parameters of the cavitation field on the stability and volatility of gasoline containing bioethanol, the content of narrow fractions in the composition of motor gasoline A-92 and three fuel samples were experimentally determined. The content of fractions boiling away at temperatures of $70{ }^{\circ} \mathrm{C}, 100{ }^{\circ} \mathrm{C}$ and $150{ }^{\circ} \mathrm{C}$ in the investigated gasolines before and after cavitation treatment was determined (Fig. 3, 4).

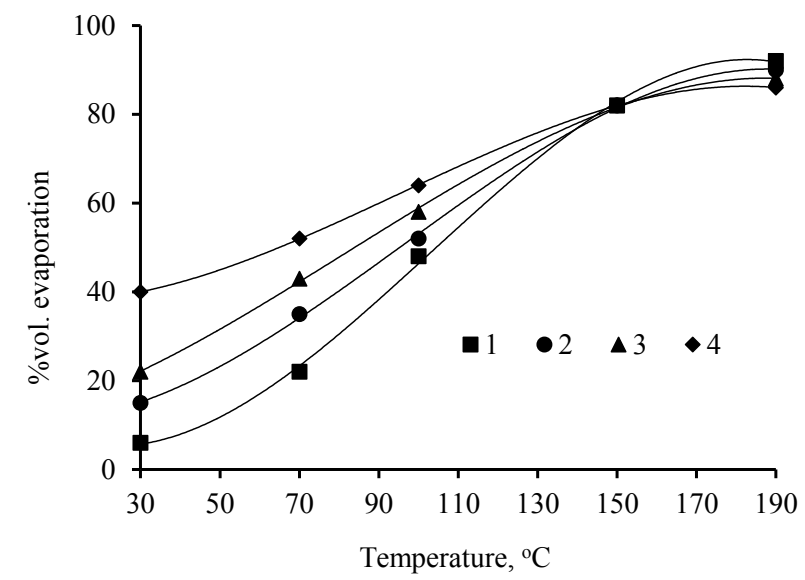

Fig. 3. Dependence of the fractional composition of A-92 gasoline, compounded with bioethanol by mechanical mixing: 1 - A-92; 2 - A-92 with the addition of $5 \%$ ethanol;

3 - A-92 with the addition of $10 \%$ ethanol; 4 - A-92 with the addition of $20 \%$ ethanol

From Fig. 3, it follows that the addition of ethanol to the composition of motor gasoline A-92 affects the volume of fuel, boils away at temperatures of $70{ }^{\circ} \mathrm{C}$ and $100{ }^{\circ} \mathrm{C}$. The volume of boiloff of fuel (compounded with bioethanol by mechanical mixing) at a temperature of $150{ }^{\circ} \mathrm{C}$ remains variable.

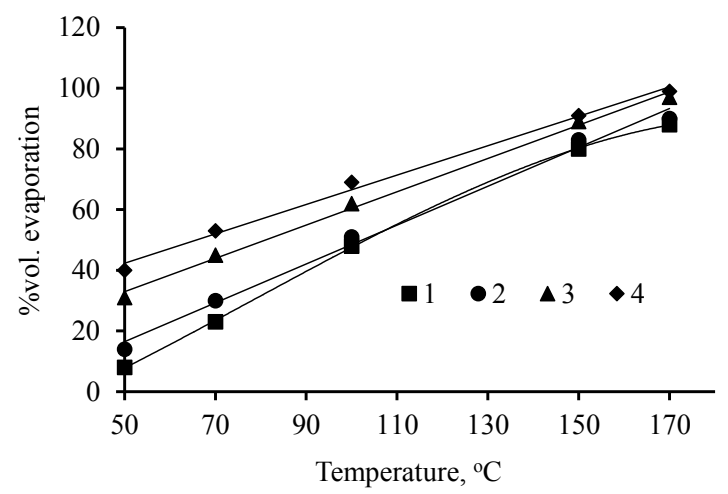

Fig. 4. Dependence of the fractional composition of A-92 gasoline, compounded with bioethanol by cavitation treatment: 1 - A-92; 2 - A-92 with the addition of $5 \%$ ethanol;

3 - A-92 with the addition of $10 \%$ ethanol; 4 - A-92 with the addition of $20 \%$ ethanol 
From Fig. 4, it can be concluded that the addition of bioethanol to the composition of motor gasoline A-92 and cavitation treatment affects the volume of fuel, boils away at a temperature of both $343 \mathrm{~K}, 373 \mathrm{~K}$ and at a temperature of $423 \mathrm{~K}$. The greatest changes occurred with samples of motor gasoline containing its composition is $10 \%$ and $20 \%$ bioethanol. For these samples, a decrease in the initial boiling point is observed in comparison with samples prepared by mechanical compounding.

In order to better understand the influence of the cavitation method for preparing gasoline-bioethanol mixtures on the hydrocarbon composition of motor gasoline and on the volatility, depending on the compounding method, the prototypes of gasoline were distilled into narrow fractions, after changing the volume of which preliminary conclusions can be drawn about the efficiency of the process $1-55^{\circ} \mathrm{C}$ (contains mainly alkanes) $2-55-95^{\circ} \mathrm{C}$ (contains benzene and bioethanol) $3-95-125{ }^{\circ} \mathrm{C}$ (contains toluene) $4-125-150{ }^{\circ} \mathrm{C}$ (contains xylenes) $5-150-$ e.b. The results are shown in Fig. 5-7. For a fuel sample with an ethanol content of $5 \%$, a decrease in the content of the $-55{ }^{\circ} \mathrm{C}$ fraction from $28 \%$ to $26 \%$ is observed; an increase in the content of the fraction $55-95{ }^{\circ} \mathrm{C}$ from $18 \%$ to $20 \%$; reducing the content of the fraction $95-125{ }^{\circ} \mathrm{C}$ from $20 \%$ to $19.5 \%$; fractions $95-125{ }^{\circ} \mathrm{C}$ from 14.2 to $13.4 \%$; fractions $150-$ e.b. from $16 \%$ to $15.6 \%$.

Analyzing the results obtained, it is possible to see that there is a change in the percentage of fractions in the composition of motor gasoline, compounded both by mechanical mixing and by means of dynamic cavitation.

For a fuel sample with an ethanol content of $10 \%$, there is an increase in the content of the $-55^{\circ} \mathrm{C}$ fraction from $30 \%$ to $37 \%$; a decrease in the content of the $55-95{ }^{\circ} \mathrm{C}$ fraction from $21.8 \%$ to $18.6 \%$; reducing the content of the fraction $95-125{ }^{\circ} \mathrm{C}$ from $16 \%$ to $7 \%$; increase in the content of fraction 150 - from $14 \%$ to $24 \%$; reduction of the fraction $95-125^{\circ} \mathrm{C}$ from 11.5 to $10 \%$.

For a fuel sample with an ethanol content of $20 \%$, a decrease in the content of the fraction is observed $-55{ }^{\circ} \mathrm{C}$ from $32 \%$ to $23 \%$; an increase in the content of the fraction $55-95{ }^{\circ} \mathrm{C}$ from $23 \%$ to $43 \%$; reducing the content of the fraction $95-125^{\circ} \mathrm{C}$ from $13.1 \%$ to $6 \%$; fractions $150-$ e.b. from $14 \%$ to $12.8 \%$; fractions $95-125{ }^{\circ} \mathrm{C}$ from 13.7 to $12.7 \%$.

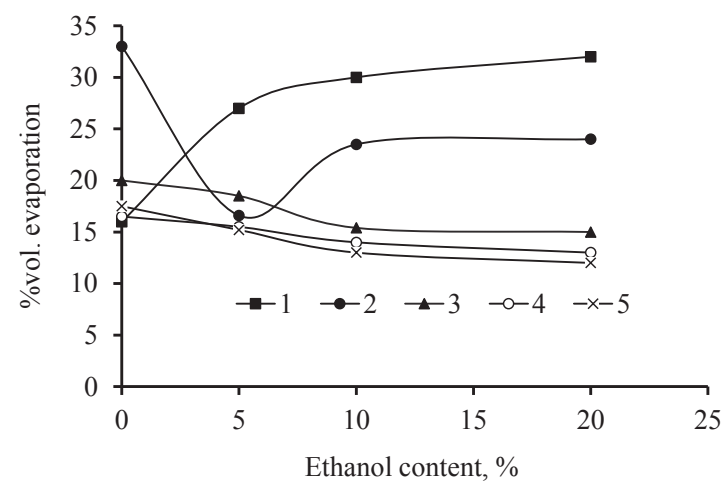

Fig. 5. Dependence of the content of narrow fractions of A-92 gasoline when modifying bioethanol (mechanical mixing): $1--55^{\circ} \mathrm{C} ; 2-55-95{ }^{\circ} \mathrm{C} ; 3-95-125^{\circ} \mathrm{C}$; $4-125-150{ }^{\circ} \mathrm{C}$ (contains xylenes); $5-150-$ e.b.

Based on the results of studying the effect of the compounding image of bioethanol-gasoline mixtures on the volatility, the saturated vapor pressure was additionally determined (Fig. 7).

The results obtained makes it possible to establish that the addition of $5 \%$ and $10 \%$ of bioethanol to fuel samples, a decrease in the saturated vapor pressure is observed when preparing mixtures using cavitation mixing. And for a fuel sample with an ethanol content of $20 \%$, a significant increase in the saturated vapor pressure is observed. This can be explained by the change in the amount of the content of volatile fractions in the samples under study during their compounding by the cavitation method, compared with the mechanical method of preparing mixtures.

The content of benzene, the amount of alkanes, the amount of olefins, the amount of aromatic hydrocarbons, the amount of ethers was determined chromatographically and is given in Table $\mathbf{1}$. 


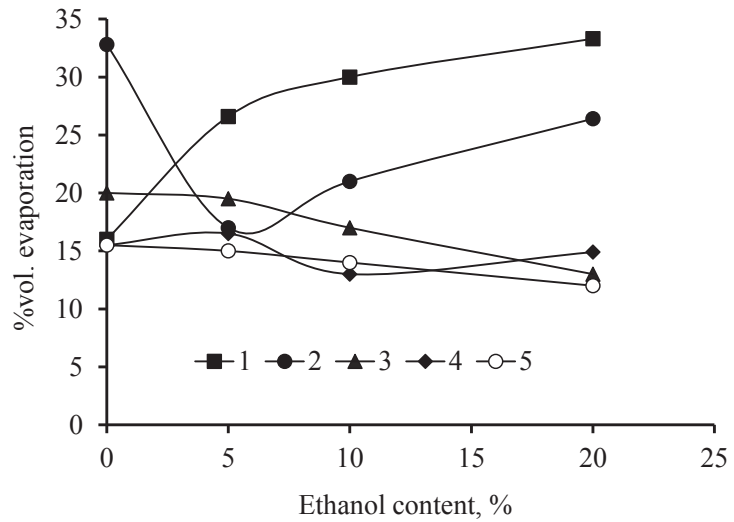

Fig. 6. Dependence of the content of narrow fractions of A-92 gasoline when modifying bioethanol (mechanical mixing in combination with cavitation treatment):

$1--55^{\circ} \mathrm{C} ; 2-55-95{ }^{\circ} \mathrm{C} ; 3-95-125^{\circ} \mathrm{C} ; 4-125-150{ }^{\circ} \mathrm{C}$ (contains xylenes); 5 - 150-e.b.

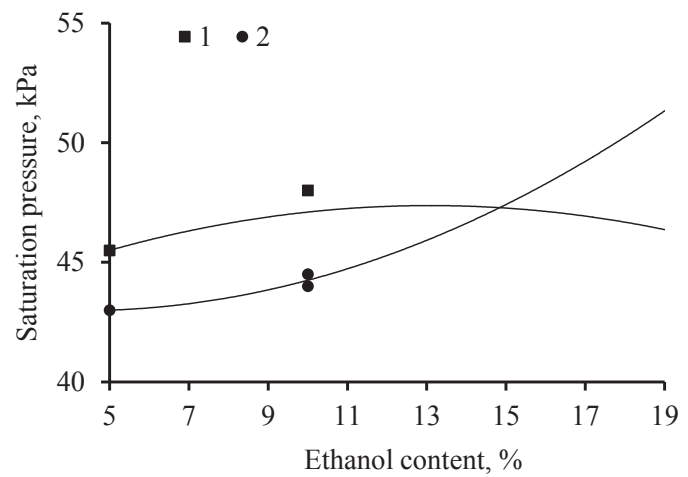

Fig. 7. Dependence of the saturated vapor pressure of A-92 gasoline, compounded bioethanol:

1 - mechanical mixing; 2 - cavitation mixing

Table 1

Content of certain classes of hydrocarbons in the studied samples of A-92 gasoline, modified bioethanol under cavitation treatment

\begin{tabular}{|c|c|c|c|c|c|}
\hline \multirow{2}{*}{ No. } & \multirow{2}{*}{$\begin{array}{l}\text { Individual hydrocarbon, class of hydrocarbons contained } \\
\text { in the sample }\end{array}$} & \multicolumn{4}{|c|}{ Volume fraction of added bioethanol, \% } \\
\hline & & $\mathbf{0}$ & 5 & 10 & 20 \\
\hline \multicolumn{6}{|c|}{ Mechanical mixing } \\
\hline 1 & benzene & 0.4 & 0.38 & 0.36 & 0.32 \\
\hline 2 & sum of alkanes & 37.2 & 35.6 & 33.5 & 29.8 \\
\hline 3 & sum of olefins & 13.5 & 12.8 & 12.1 & 10.8 \\
\hline 4 & sum of aromatic compounds (benzene) & 33.7 & 32.1 & 30.3 & 27.0 \\
\hline 5 & amount of naphthenes & 12.4 & 11.8 & 11.2 & 9.9 \\
\hline 6 & amount of ethers & 0.0 & 0.0 & 0.0 & 0.0 \\
\hline \multicolumn{6}{|c|}{ Cavitation treatment } \\
\hline 7 & benzene & 0.41 & 0.39 & 0.38 & 0.33 \\
\hline 8 & sum of alkanes & 35.1 & 33.2 & 31.1 & 28.0 \\
\hline 9 & sum of olefins & 13.9 & 13.1 & 12.6 & 11.4 \\
\hline 10 & sum of aromatic compounds (benzene) & 33.9 & 32.5 & 30.8 & 27.6 \\
\hline 11 & sum of naphthenes & 12.6 & 12.1 & 11.7 & 10.3 \\
\hline 12 & sum of ethers & 0.02 & 0.15 & 0.31 & 0.52 \\
\hline
\end{tabular}




\section{Discussion of the research results of the influence of the parameters of the cavitation field on the physical stability of gasoline}

The results obtained are explained by the fact that chemical transformations of representatives of almost all classes of hydrocarbons occur in the cavitation field. The source of these transformations is the energy of the cavitation field, which causes the formation of free alkyl radicals in the reaction volume and begins a series of radical-chain transformations, the end products of which are high-octane components of gasoline.

The maximum rate of a chemical reaction under experimental conditions is observed for alkane hydrocarbons, the concentration of which decreases by almost $2 \%$. In this case, the content of unsaturated hydrocarbons (olefins, arenes) and cycloalkanes increases by a comparable value. It should be noted that these particular products are used as high-octane additives to base gasoline in the classic production method. Thus, the proposed method for modifying gasoline with bioethanol in a cavitation field should be considered as a promising technology for producing high-octane motor gasolines.

The introduction of bioethanol into the composition of gasoline leads to an improvement in its volatility. In this case, cavitation treatment makes it possible to obtain a mixture resistant to delamination. There are some limitations of the research parameters: the pressure in front of the nozzle is up to $11 \mathrm{MPa}$, the maximum flow rate of the mixture is $51 / \mathrm{min}$ and the temperature is $293 \mathrm{~K}$. The lack of research on the problem of homogeneous mixing of gasoline and alcohol in a given proportion necessitates the development of an additional dispenser. The state standard limits the content of alcohols, ethers, benzene, aromatic hydrocarbons in commercial motor gasoline. Research should be aimed at determining the process parameters that will ensure compliance with the legislation on the composition of the product with the available technology capabilities.

The results obtained made it possible to establish that the addition of a biocomponent (ethyl alcohol) to the fuel samples in amounts of $5 \%$ and $10 \%$ leads to a decrease in the saturated vapor pressure when preparing mixtures using cavitation mixing. And for a fuel sample with an ethanol content of $20 \%$, a significant increase in the saturated vapor pressure is observed. This can be explained by the change in the amount of the content of volatile fractions in the samples under study during their compounding by the cavitation method, compared with the mechanical method of preparing mixtures.

The vapor pressure can be changed by cavitation treatment -this allows the production of bioethanol-gasoline automotive mixtures, suitable for use in various climatic conditions, by exposure to cavitation exclusively. This makes cavitation technology promising for the development of energy-efficient methods for the production of gasoline.

\section{Conclusions}

The laboratory unit for cavitation treatment of gasoline mixtures has been modernized to study the effect of the intensity and number of cavitation cycles on the fractional composition and volatility, which will allow choosing the optimal parameters to achieve the specified quality indicators of gasoline with minimal energy consumption.

It is found that the introduction of bioethanol into the composition of gasoline leads to an improvement in its volatility. In this case, cavitation treatment makes it possible to obtain a mixture resistant to delamination.

The addition of bioethanol leads to an adequate increase in light fractions during mechanical mixing and to a change in the fractional composition of the bioethanol-gasoline mixture during cavitation treatment.

The addition of bioethanol in amounts up to $10 \%$ leads to a decrease in the saturated vapor pressure during cavitation treatment of bioethanol-gasoline mixtures, and an increase in the bioethanol content up to $20 \%$ leads to an increase in the saturated vapor pressure, which is explained by a change in the chemical composition of fuel components in comparison with the mechanical method of preparing mixtures.

Cavitation treatment makes it possible to change the fractional composition, saturated vapor pressure and the volatility of bioethanol-gasoline mixtures, making cavitation a promising energy-saving gasoline production process for various climatic conditions. 


\section{References}

[1] Emel'yanov, V. E. (2003). Vse o toplive. Avtomobil'niy benzin: svoystva, assortiment, primenenie. Moscow, 79. Available at: https://search.rsl.ru/ru/record/01002395737

[2] Milotskiy, V. V., Ganja, S. N. (2013). Meetod of increase of antikok value of gascondensaishn petrols. Visnyk Skhidnoukrainskoho natsionalnoho universytetu imeni Volodymyra Dalia, 14 (203), 85-88.

[3] Fedotkin, I. M., Guliy, I. S. (2000). Kavitatsiya: Kavitatsionnaya tehnika i tehnologiya, ih ispol'zovanie v promyshlennosti. Ch. 2: Teoreticheskie osnovy proizvodstva izbytochnoy energii, raschet i konstruirovanie kavitatsionnyh teplogeneratorov. Kyiv: OKO, 898. Available at: https://search.rsl.ru/ru/record/01000857395

[4] Sun, M., Zucker, I., Davenport, D. M., Zhou, X., Qu, J., Elimelech, M. (2018). Reactive, Self-Cleaning Ultrafiltration Membrane Functionalized with Iron Oxychloride Nanocatalysts. Environmental Science \& Technology, 52 (15), 8674-8683. doi: https://doi.org/10.1021/acs.est.8b01916

[5] Wang, X., Wang, J., Guo, P., Guo, W., Wang, C. (2009). Degradation of rhodamine B in aqueous solution by using swirling jet-induced cavitation combined with H2O2. Journal of Hazardous Materials, 169 (1-3), 486-491. doi: https://oi.org/10.1016/ j.jhazmat.2009.03.122

[6] Zakharov, I. I., Ijagbuji, A. A., Tselishtev, A. B., Loriya, M. G., Fedotov, R. N. (2015). The new pathway for methanol synthesis: Generation of methyl radicals from alkanes. Journal of Environmental Chemical Engineering, 3 (1), 405-412. doi: https:// doi.org/10.1016/j.jece.2014.08.008

[7] Ivchenko, V. M., Kulagin, V. A., Nemchin, A. F. (1990). Kavitacionnaya tehnologiya. Krasnoyarsk, 200. Available at: http:// research.sfu-kras.ru/publications/publication/251448528-839458427

[8] Tselischev, A., Loriya, M., Nosach, V. (2016). Investigation of cavitational transformation of motor fuels. Technology Audit and Production Reserves, 4 (4 (30)), 26-32. doi: https://doi.org/10.15587/2312-8372.2016.76528

[9] Nagiev, T. M. (2015). The Theory of Coherent Synchronized Reactions: Chemical Interference Logics. International Journal of Chemical Engineering and Applications, 6 (5), 293-305. doi: https://doi.org/10.7763/ijcea.2015.v6.500

[10] Kravchenko, O. V., Suvorova, I. G., Baranov, I. A. (2014). Method of determining the effectiveness of hydrocavitation treatment in technologies for producing and combusting composition fuels. Journal of Mechanical Engineering, 17 (2), 58-62. Available at: http://journals.uran.ua/jme/article/view/27201/36465 